\section{ORIGTIAL COMMUUTICATIOIS.}

\section{ON THE DIAGNOSIS OF UR AMIC BLIND- NESS AND DYSPNOEA.}

[Excerpt from a Clinical Lecture.]

By W. H. WALSHE, M.D., F.R.C.P.Lond., Professor of Medicine and Clinical IIedicine in University College, Loudon;

Physician to University College Hospital; etc., etc.

I HAVE recently seen, out of doors, a very striking example of uremic blindness; one illustrating so plainly the occasional difficulties of its diagnosis, that I will arail myself of the particulars for the discussion of the general question.

Case. On the 12th of November last, Mr. J. R. Wells brought me a patient of his, under the following circumstances:-

"Mr. _ aged 29, widower, leading a steady and quiet life, has generally enjoyed good health. Ten years ago, he had a peculiar contraction of the right leg, the tendons feeling stiff in the ham. Three years ago, he was ill for a fortnight with sore throat. He has now been ill for upwards of two months. A fortnight ago, boils commenced to form about his body; one, above the left orbit was followed by great pain on the spot. All of these boils got well; ho felt generally ill and depressed, but was improving, when ten days ago, he found he could not see as usual; the left eye being decidedly the worse of the two. He had no cephalalgia, nor swelling of the face.

"Nov. 12th. Present State. (a) He looks depressed, somewhat stupid; has slept badly for last two nights, with out bad dreams; spirits low ; temper of late rather morose inclined to talk to himself. (b) The skin is pale and sallow; he does not perspire; there is no skin affection of any kind; no distinct swelling about eyelids; he says they are stiff; no swelling of ankles. (c) The legs are weak, about equally so; if any difference, the left is the worse (vide $k$ ). (d) Tongue tolerably clean; bowels open from medicine; anorexia. (e) Resonance is good under clavicles; no chest symptoms. ( $f$ ) Heart's action is rather too extensively felt; first sound at base and apex rather too clear and full; no murmur at heart (pulse 76); strong venous hum in neck. (g) No swollen lymphatic glands. (h) Urinary organs patient declares to be in good order; three years ago, however, he had hamaturia, for which he knew no cause. (k) Moderate headache at vertex; no vertigo; no tinnitus; no peculiar sensations of any kind in head; intellect perfectly clear; some stiffncss in joints of upper extremities, shoulders most, right and left the same; he squeezes awkwardly with left hand, but about as forcibly as with right; no deviation of tongue; articulation quite distinct; no peculiar sensations in limbs. (l) No convulsive movements anywhere. (m) Pupils medium sized, round; contract immediately and gently well under light (merely that of the room); then expand a little; the action is not distinctly different on the two sides; no opacity in either eye; no amaurotic look ; no photopsia ; no musca ; and no spontaneous pain in the.eye-balls; no photophobia, but is pained, he thinks, by continuing the effort to see; he cannot distinguish moderate sized objects at opposite side of the street; cannot read small print at all; sees better in morning when gets up, and with strong light ; has never had diplopia."

Herc, then, was an anæmic person, suffering from boils (which were, as is well known, epidemic at the time), but caring neither for his anæmia, nor his boils, nor the general disturbance of health accompanying these, but solely anxious about the sudden and increasing failure of his eight.

Were the eyes themselves diseased? No opacity could be discovered in either; membranes and humours appearcd perfectly transparent. That the cornea, chambers, lens, and its capsule, were free from any change sufficient to explain the symptoms, was, in fact, unquestionable. Again, disease of the retina, producing blindness, if acute, would have been attended with local symptoms, weight and ful- ness in the eyeball, with throbbing pain, photopsia, change of colour of the irides, etc., and with ferer-conditions all of them wanting here. Chronic retinitis is attended with morbid sensibility to light, which our patient did not complain of. It is so infinitely unlikely that tumours connected with the deep seated tissues of the eye should form simultaneously in both organs, that the idea of their existence here might, almost without examining the globes themselves, be rejected. Disease of the optic nerves, or their sheaths, eularges the pupil, paralyses the iris, and very, very rarely attacks both sides simultaneously: it was, therefore, not the cause of the blindness here.

Nor could the case be supposed one of idiopathic amaurosis. The eyes had not the amaurotic look nor expression; there was no lustre of their surface, no rolling or unsteady movements of the eyeballs, and none of the peculiar vacant gaze of that affection. This patient, on the contrary, directing the axes of the eyes appropriately, looked as if he could see roell.

The least reflection on the condition of the patient's motor and intellectual faculties satisfies us that none of the ordinary affections of the brain could have existed here. Neither meningitis, simple or tuberculous, nor hæmorrhage, produce blindness of the type before us; and, though both acute and chronic softening do actually cause impairment of vision on one, or even on both sides, blindness never constitutes the prominent symptom it did here; besides, all other evidences of softening were deficient.

But it was not so easy to exclude tumour of the encephalon. For not only has blindness, more or less complete, been a frequent symptom in cases of intra-cranial morbid growth, but actually, next to cephalalgia, their most. or nearly their most, frequent symptom. This is true of tumours of the cerebrum, cerebellum, pons, and pituitary gland; a circumstance showing, by the bye, the vainness of the attempts to diagnosticate the seat of a cerebral tumour, solely through the perversion of special senses. It is true that there was no cephalalgia of note in this instance, but cephalalgia may be absent from first to last, even in protracted cases; and we might have been at the commencing period of the formation, at which period, there is every reason to believe, if not to be absolutely certain, the head is often free from pain. Intra-cranial tumour was, therefore, by possibility the cause of the failure of vision in this patient.

But, again, there are cases on record, tending to show that injuries to the supra-orbitar nerve may produce obscurity of vision, nay, complete blindness. It is true that some observers hold that, in all such alleged cases, there has in point of fact been concussion of, or other injury to, the eyeball itself; but the weight of the evidence seems to me decidedly in favour of injury to the branch of the fifth nerve named sufficing to impair vision. Now the patient had had no traumatic mischief done to his eyebrows, it is certain; but he had had a boil there, the source of much pain and irritation; and it seemed an admissible hypothesis that the local inflammation might have acted the part of a wound in the spot. It is alleged that the nerve of one side only being implicated, the eye of the other has suffered by sympathy.

It was certain the patient had not been taking any of the drugs-belladonna, aconite, stramonium, etc.-which injure sight.* Besides, the pupils were not dilated.

Hæmic or blood-diseases (I use the adjective as more euphonious) are many of them, more or less constantly, attended with perverted vision. Now our patient was anæmic to a high degree; but I could not admit this to be the cause of his blindness; for theugh impairment and perversion of sight often attend this state, they never, as far as I know, do so to the extent observed here: they never constitute the prominent enduring symptom of the state. But anæmia might here be fairly taxed with increasing the blindness, though essentially otherwise caused.

But however plausible it might have appeared to refer

- Perry, I. C. H., Mules, vol. ix, p. 105, admitted January 6th, 1853 after taking half an ounce of salts of lemon, had considerable deficiency of vight, when soen eightoon hours later. 
the imperfect sight either to encephalic tumour, or to implication of the frontal nerve, examination of the urine, a plication of the frontal nerve, examination ar a much more satisfactory clue to the symptom. The fluid was highly albuminous. We now ascertained from relatives that the daily amount was small (a fact previously denied by the patient). A few days later, the eyelids were distinctly, though very slightly, odematous; the ankles remained free from dropsy throughout. The most active measures failed to produce any secretion from the skin, which continued to the last day dry and harsh.

Between this period and that of the patient's death, on the 29 th of November, one or two circumstances occurred worthy of note. The hydrochloric acid test succeeded strikingly; the expired air gave thick opaque fumes: but in this instance, as in many we have seen in the wards together, the l,reath was of strongly urinous odour-a state quite as significant of uramia, as an affirmative result by Frerichs's test. For several days before his decease, the paticnt had uscemic dysprecee, as I would call it-a dyspnoea evidently depending on the morlid state of the blood: for there was no pulmonary nor carliac affection to explain it; the percussion-sound was excellent everywhere; there was no rhonchus, no scrious alteration of the respiration-sound, and no cardiac disease. The pulse-respiration ratio averaged during this time $3: 1$, both pulse and respiration being, absolutely speuking, very frequent, namely 120 and 40 . But there was an amount of breathing distress materially greater thin attends a respiration of forty per minute: to this the poisoned blood was the apparent cluc.

Now, remarkably enough, this patient remained, almost to the last moment, free from the more ordinary effects of uremic poisoning. The brain and cord gave no sign of suffering; his intellect continued clear; there was neither delirium nor sopor; and convulsions did not occur. This dissection of the effects of the kind of poisoning in question is not uncommon: the brain and vision may alone be affected; or the vision, the functions of the spinal cord, and those of the brain may suffer simultaneously.

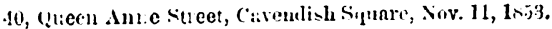

\section{REPORT OF TIIE READING PATHOLOGICAI SOCIETY.}

I3y W. W. MIOXILAY, Esq.

[concludid from p. !e!c of last number.]

DISFASES OF THE VASCCLAR SYSTEM.

IIYpertropily of IIfart : DISEase of Aortic Valves:

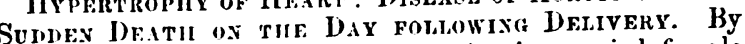
W. B. Yousc, Esil. (Sept. 1st, 185\%) A married female was ielivered of her seventh child on the morning of 21 st Aurust, 18.5. S. She had a natural labour. On the following morning, she suldenly expired after taking some tea and bread and butter.

Exrmination of the Body. The omentum was loaled with fat, the stomach and bowels were much distended with flatus, and the liver was enlarged; the uterus was fully contracted, containing no clots ; the right kidney was fully contracted, containing no clored in structure-the left was natural; the cavity of the chest was rather contracted, and the lungs were congested; the heart was larger than normal; the left ventricle was hypertrophied, and contained diuk clots; the aortic valves were thickened and rigid; the right ventricle was small, atrophied, and quite empty.

Ir. Young considered that the disease of the heart had been the cause of death, and that its function had been arrested by the distended state of the stomach, and large size of the liver.

Mixep or Conpound Aneurigm of the Aorta. By C. II. G.amble, Esq. The ascending aorta and arch were dilated to twice their natural size; while the upper part of the descending portion presented in addition a rupture of its coats, and a sac communicating with it as large as an orange. The two upper dorsal vertebre were eroded by the pressure, and formed a boundary to the sac; this part of it was the only one containing coagulum. The patient was a brewer's man, aged 54. He had continued his employment, with temporary intervals, until within a few days: of his death. He died after excitement, which had produced rupture of the sac and effusion of blood into the right thoracic cavity. The right lung was emphysematous; it lay across the front of the pleural cavity under the sternum. Three pints or more of blood were found effused into this cavity.

Diffused Popliteal Aneurism. By F. A. Bullex, Esq. The patient was W. B., a man in the Royal Berkshire Hospital, whose thigh Mr. Bulley had amputated a few days ago, on account of threatened sloughing. The man stated, on his admission on dugust 21st, that eleven months previously he experienced, after having carried a sack of wheat up some steps, a tingling sensation in front of the right knee. If noticed also a small swelling, not larger than a pea, in the ham; this and the tingling sensation disappeared in a few days. On the 23rd June, he again noticed the swelling, and he had some throbbing in it, and also pricking sensations up the inner side of the thigh. The tumour reached the size of a pigeon's egg. On the morning of his admission into the hospital, he was engaged in hoeing turnips; he felt something give way in the ham, and experienced rushing sensations down the leg, and up the thigh, in the course of the femoral artery. The limb became disabled, and the leg and foot numb and celematous. The popliteal swelling rapidly increased in size, and he had sensations of burning in parts of the leg, etc. Pressure was tried by means of Mr. Bulley's tourniquet; but, the patient being obstinate, the plan was not properly carried out, and amputation became the only resource, gangrene being threatened, and the man being in a very cachectic and exhausted state.

There were found on dissection the sacs; one, the larger and posterior, contained much covagula, and was formed by the surrounding textlires (fascia lata, gastrocnemii, and hamstring muscies, cellular tissue, etc.); the smaller, communicating directly with the artery through a longitudinal aperture, had more distinct parietes, continuous with the coats of the artery, but lost posteriorly in the mass of coagula of the larger cyst. The arteries were healthy above and below. The man made a slow but good recovery.

Mr. Bulley thought pressure had one inconvenience attached to it; viz., that it might da the separation of a thickening its coats, so as to render the se thought the collaligature difficult and dangerous.

cral arteries had be limit the trial of pressure to cases of Mr. May would lism, where the sac was entire; or where, circumscribed aneurism, a second sac had formed from the condensation of cellular tissue by inflammation.

Diseased Arteries in a Patiest Dyisg of Ganghene. By F. A. Bulley, Esq. (Harch 23rd, 1853.) Mr. Bulley prosented some specimens of arterial disease taken from a prosented some spo had lately died in the hospital with woman aged 68 , who had lately died in the hospital with dry gangrene of the right hand and arm. She had been exposed to cold in hanging up some clothes in her garden, and had a rigor, followed by fit, soon after. One night, having previously complained of smarting in the hand, she had great pain in it and in the wrist; she found they were of a dark colour; this change extended upwards, and had of a dark colour; the whole of the forearn, the hand and arm being a dry black and charred looking mass. Some of the toes were gangrenous, but there was more action in the neighbouring parts; so that the gangrenous parts were not so dry. She had for years been subject to cold extremities, shewing great feebleness of circulation.

Examination of the Body. The main arteries were examined. The right brachial artery was blocked by a firm adherent coagulum for two or three inches; the lining adhe artery shewing dark discoloration through membrane of the artery shewing dark discoloration affected 